\title{
Teknologi Informasi dan Komunikasi untuk Pariwisata: Analisa Isi Laman Resmi Pariwisata Provinsi Kepulauan Riau
}

\section{Information Communication Technology for Tourism: A Content Analysis on Tourism Official Page of Kepulauan Riau Province}

\author{
Budiarjo \\ Universitas Sebelas Maret \\ budiarjo-uns@hotmail.com
}

\begin{abstract}
Abstrak
Penemuan Teknologi Informasi dan Komunikasi (TIK) telah mengubah cara hidup manusia. Penerapan TIK di bidang pariwisata telah membawa perubahan drastis di kalangan pebisnis pariwisata, wisatawan, dan pemerintah. Dalam memasarkan objek wisata, pemerintah sekarang ini tidak lagi perlu menghabiskan uang dalam mengorganisir pameran, tetapi cukup menggunakan laman yang jauh lebih murah. Provinsi Kepulauan Riau menggunakan laman berjudul Wonderful Kepri, http://Kepri.travel/ sebagai sarana informasi dan pemasaran destinasi pariwisata di wilayahnya. Tujuan dari penelitian ini adalah untuk menggambarkan sejauh mana suatu manfaat laman resmi kepada pelanggan. Penelitian ini menggunakan metode analisis isi baik pada teks atau gambar di website. Hasil penelitian ini menunjukkan website menyediakan berbagai menu, menarik dan informatif bagi wisatawan atau siapa pun yang tertarik untuk mengunjugi Kepulauan Riau.
\end{abstract}

Kata kunci: Tehnologi Informasi dan Komunikasi, pariwisata, laman, Kepulauan Riau

\begin{abstract}
The invention of information communication technology (ICT) has changed human's lifestyle. The application of ICT to tourism sector has brought abut dramatic change among tourism business performer, tourists, and government. I marketing tourist object, the government no longer needs to use up all of its money today to organize an exhibition, it can use webpage only with much cheaper cost. Riau Islands Province use page entitled Wonderful Kepri (Kepulauan Riau = Riau Islands), in http://Kepri.travel/, as the medium of information and marketing the tourism destination in its area. The objective of research was to describe the extent to which an official page is beneficial to the customers. This research employed content analysis on both texts and figures in the website. The result of research showed that this website provided a variety of menus, was attractive and informative to tourists or everyone interested in visiting Kepulauan Riau
\end{abstract}

Keywords: Information Communication Technology, tourism, webpage, Kepulauan Riau 
Gambar 1. Halaman Depan Laman Pariwisata Kepulauan Riau

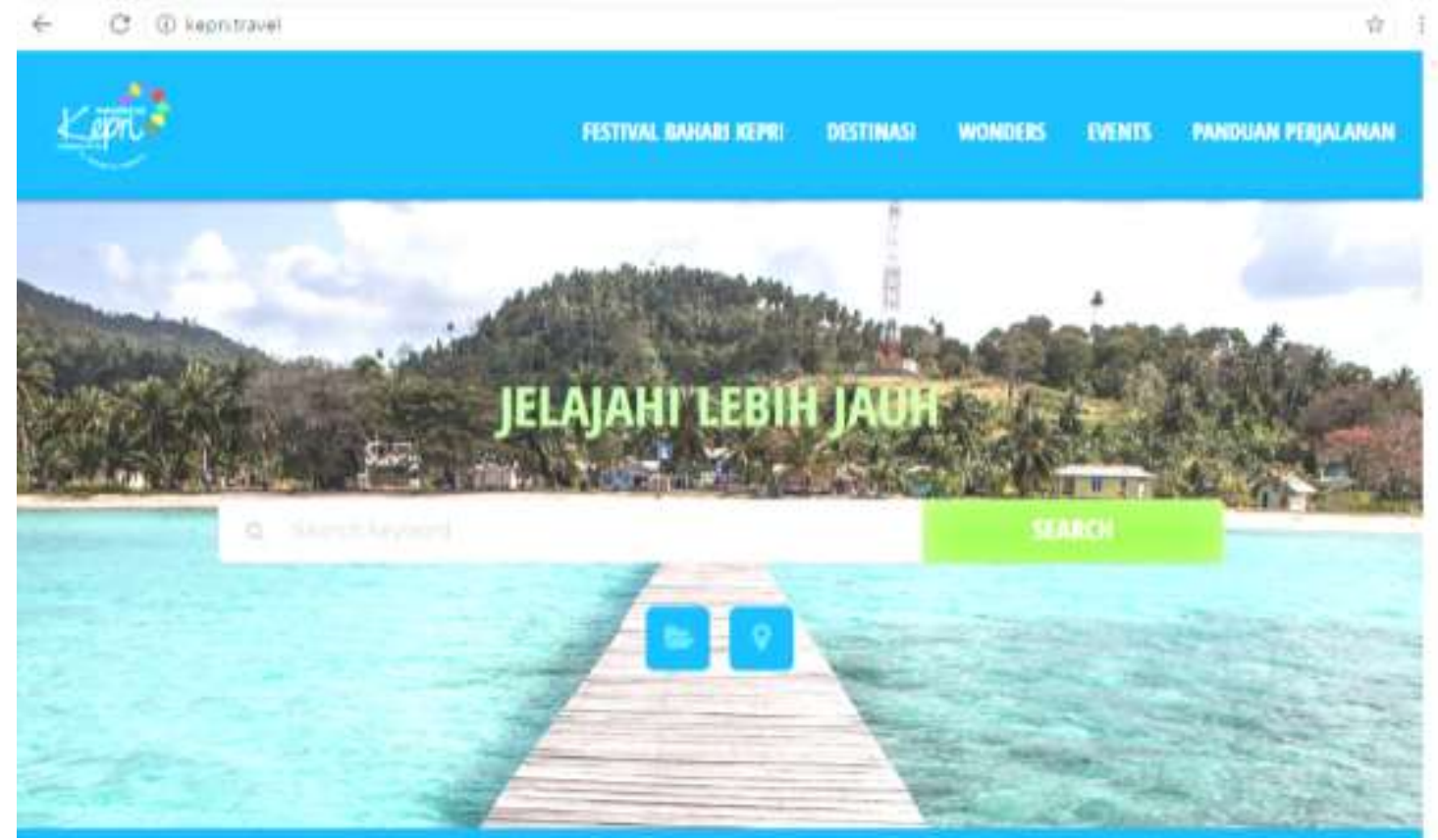

Sumber: http://Kepri.travel/

\section{Pendahuluan}

Penemuan Tehnologi Informasi dan Komunikasi (TIK) telah mengubah cara hidup manusia. Penerapan TIK di bidang pariwisata telah membawa perubahan drastis di kalangan pebisnis pariwisata, wisatawan,dan pemerintah. Dalam memasarkan objek wisata, misalnya, pemerintah sekarang tidak lagi perlu menghabiskan uang dalam mengorganisir pameran secara besar-besaran, tetapi cukup menggunakan laman yang jauh lebih murah. Bagi wisatawan, mereka tidak memerlukan lagi buku panduan wisata yang tebal, tetapi cukup dengan melihat laman yang ada di komputer, komputer jinjing maupun telepon genggam.

Tehnologi Informasi dan Komunikasi telah mengubah sudut pandangan pariwisata sebagaimana pernah diungkapkan oleh beberapa ahli: "With new communication technologies the individual is clearly an active participant in indexing and dragging. Personal computers with e-mail facilities enable the individual to combine elements from fictional and factual representational files" (Hallet \& Weinger 2010, p. 3). Sementara itu, Ritzer \& Liska menyatakan secara ekstrim mengenai pariwisata: "In our post-Modern world '... the post-tourist finds it less and less necessary to leave home; technologies. . . allow people to "gaze" on tourist sites without leaving home" (Ritzer \& Liska, 1997: 102). Namun demikian, masih banyak wisatawan yang cenderung mengunjungi tempat tujuan secara langsung untuk mendapatkan pengalaman nyata.

Provinsi Kepulauan Riau (Kepri) merupakan provinsi tujuan pariwisata ketiga di Indonesia yang paling banyak 
dikunjungi oleh wisatawan setelah Bali dan Jakarta. Provinsi ini menggunakan situs berjudul Wonderful Kepri dengan alamat laman http://Kepri.travel/ sebagai sarana informasi dan pemasaran destinasi pariwisata di wilayahnya. Tujuan dari penelitian ini adalah untuk menggambarkan sejauh mana manfaat laman resmi pariwisata Provinsi Kepri untuk menarik wisatawan, baik domestik maupun manca negara. Penelitian ini menggunakan metode analisis isi baik pada teks maupun pada gambar yang tercantum di laman.

\section{Metode Penelitian}

Penelitian ini menggunakan teknik analisis isi kualitatif untuk membedah persoalan yang diajukan yakni mengenai citra pariwisata Kepulauan Riau pada laman resmi http://Kepri.travel/. Analisis isi kualitatif diartikan sebagai metode riset untuk interpretasi subjektif dari isi data melalui proses klasifikasi sistematis, koding dan indentifikasi tema/pola (Hsieh \& Shannon, dalam Putra dan Saputri, 2012). Penelitian ini berfokus pada karakteristik bahasa sebagai komunikasi dengan perhatian pada isi atau arti kontekstual teks.

Subjek penelitian ini adalah laman http://Kepri.travel/. Sedangkan obyek dari penelitian ini adalah tourism branding yang ada pada laman tersebut. Unit analisis penelitian ini adalah mengacu pada teori Media Richness Theory (MRT) untuk melihat "kekayaan media" yang dalam hal ini adalah laman. Laman merupakan media yang dapat memfasilitasi kebutuhan untuk mengkomunikasikan program kebijakan tertentu (Lodhia, dalam Putra dan Saputri, 2012: 28).

Mengadopsi teori MRT, maka unit analisis fitur laman obyek penelitian ini meliputi Ketepatan Waktu (kesegeraan), Keragaman (penerima, isyarat, bahasa), Sumber Personal, Memori Terolah melalui komputer, Perekaman Eksternal dan Konkurensi.

\section{Pembahasan}

\section{Ketepatan Waktu (Kesegeraan)}

Kesegeraan di sini dimaksudkan merujuk kepada kemampuan media (laman) dalam menyediakan informasi secara berkala dan memungkinkan umpan balik secara cepat. Jika dilihat dalam isi laman http://Kepri.travel/ maka dapat disampaikan bahwa laman tersebut memenuhi unsur kesegeraan informasi yakni dipublikasikannya kegiatan-kegiatan aktual yang menjadi agenda dari promosi pariwisata di Kepulauan Riau.

Hal ini terlihat dari rentetan agenda kegiatan beserta tanggal kegiatannya seperti yang termuat pada menu "Jadwal" yakni Kepri Carnaval, Seminar Marine Tourism, Marine Tourism Investation Forum, Gala Dinner FBK, Jong Competition, Diplomatic Tour, City Tour dan kegiatan lainnya. Informasi yang terbaru pun juga mendapatkan tempat di laman ini seperti pada menu "Berita" yakni berita-berita mengenai kegiatan Festival Bahari Kepri 2016 maupun berita-berita aktual dari laman hyperlink. Meski demikian laman bersangkutan belum memunculkan isu-isu seputar wisata Kepri aktual dalam bentuk webcast. Webcast 
adalah siaran langsung suatu peristiwa dari media internet.

\section{Keragaman penerima}

Keragaman penerima adalah kemampuan laman untuk berkomunikasi dan menyampaikan informasi ke berbagai stakeholders. Dalam hal ini laman memiliki potensi sebagai komunikasi massa yang menjangkau pesan secara global. Untuk memastikan pesan laman bisa diakses oleh semua pihak maka salah satu indikatornya adalah tidak adanya menu mengisi username dan password. Dalam konteks ini, laman dalam http://Kepri.travel/ tidak mencantumkan menu username dan password sehingga bisa diakses oleh siapapun netter. Demikian juga dengan menu-menu lain dalam isi laman juga tidak terdapat menu username dan passwords.

Selain itu, laman http://Kepri.travel/ juga tidak menampilkan email alert atau peringatan email untuk menargetkan sebagai stakeholders. Ini berarti bahwa laman terkait memberikan kemudahan untuk mengakses sekaligus tidak memberikan batasan untuk siapapun mengakses situs terkait. Situs terkait hanya memberikan batasan bagi pengakses jika berkeinginan untuk mengirim pesan kepada pengelola situs melalui menu "kontak" yang mengharuskan pengakses mengisi nama, email, identitas pengirim dan pesan yang disampaikan.

\section{Keragaman Isyarat}

Keragaman isyarat mengacu kepada kemampuan untuk mengkomunikasi pesan melalui pendekatan berbeda-beda seperti tubuh, bahasa, suara dan intonasi. Indikator dalam konteks ini adalah di halaman laman menggunakan alat seperti grafis, animasi, multimedia (audio dan video klip) yang dimanfaatkan untuk meningkatkan presentasi laman. Pada laman http://Kepri.travel/ ditemukan sejumlah keragaman isyarat sebagai bagian dari presentasi laman dalam mempromosikan kepariwisataan di Kepri yakni menu beragam foto yang menampilkan foto-foto kegiatan kepariwisataan di Kepri dengan gambar para pengunjung di dalamnya.

Dalam foto-foto terkait menunjukkan bahasa tubuh (gesture) yang memperlihatkan kegembiraan, optimisme, solidaritas, kepedulian, kreativitas, perhatian, kerja keras, semangat, kerja sama,keanekaragaman budaya, keanekaragaman hayati, dan pesona alam. Foto-foto yang ditampilkan pun juga dipilih dengan posisi gambar (angle) yang estetis dan beragam sehingga memberikan kesan hidup dan berwarna.

Laman http://Kepri.travel/ juga menampilkan menu grafis untuk menarik tampilan situs seperti pada menu "kontak" yang juga menampilkan grafis peta Kepri. Grafis peta ini menunjukkan sejumlah lokasi yakni Kantor Gubernur Provinsi Kepri, Tanjung Pinang, Pulau Mantang, dan lain sebagainya.

Meski demikian laman ini belum menampilkan secara maksimal kanal komunikasi lain dalam isi situsnya yakni tampilan animasi dan multimedia (audio dan video klip) yang dapat dimanfaatkan untuk meningkatkan presentasi laman. Video streaming yang tersedia juga masih terbatas pada menu tertentu saja.

4. Keragaman Bahasa 
Variasi bahasa menunjukkan kemampuan penggunaan kata yang berbeda untuk meningkatkan pemahaman, yaitu pada variasi cara dalam menyampaikan ide dan konsep melalui simbol bahasa. Dalam konteks ini indikatornya adalah apakah institusi memfasilitasi para stakeholders pada lamannya dengan menggunakan hyperlink, serta menu dan format yang berbeda untuk laporan. Hyperlink dibagi menjadi internal (dalam sebuah halaman web) dan eksternal (ke Laman lain). Hyperlink digunakan untuk mengintegrasikan informasi penting.

Jika dilihat isi laman http://Kepri.travel/ maka dapat dilihat bahwa situs terkait menyediakan fasilitas hyperlink. Ini dapat dilihat dari adanya menu "Situs Kami Yang Lain" berupa hyperlink ke sejumlah laman lain ketika diakses yakni situs Wonderful Indonesia, Provinsi Kepulauan Riau, Pariwisata Batam, Bintan Breadtalking Journey, Pariwisata Natuna dan Pariwisata Tanjungpinang. Fasilitas hyperlink juga muncul pada laman ini yakni pada menu "Hubungi Kami" berupa kanal "Unduh Peta Wisata" dan "Tambah Testimoni".

Menu hyperlink juga tersedia di laman ini pada fasilitas menu "Temukan Kami" yakni hyperlink laman ke sejumlah kanal media sosial yakni Facebook, Instagram dan Twitter. Hyperlink juga muncul pada menu "Jelajahi Lebih Lanjut" dengan sambungan link ke kanal "Wonders", "Event", "Destinasi" dan "Festival Bahari Kepri”. Laman ini juga difasilitasi dengan pemakaian bahasa asing selain bahasa Indonesia sebagai bahasa pengantar akses situs yakni bahasa Inggris, Jerman, Perancis dan Mandarin (Cina). Dari ulasan tersebut maka dapat disimpulkan bahwa laman http://Kepri.travel/ memiliki fasilitas hyperlink sebagai bagian dari komunikasi promosi pariwisata di Kepri.

Selain adanya fasilitas hyperlink, aspek keragaman bahasa suatu laman juga memastikan apakah perusahaan menyediakan format file yang mencakup Portable Document Format (PDF), Hypertext Markup Language (HTML) atau beberapa yang lain format file serta memastikan apakah laporan disediakan dalam bahasa yang berbeda. Jika mengecek laman http://Kepri.travel/ maka dapat dilihat bahwa laman ini belum menyediakan fasilitas PDF dan HTML pada berbagai konten menu di dalamnya.

\section{Sumber Personal}

Sumber personal memfokuskan pada kemampuan untuk menunjukkan perasaan dan emosi. Parameter unit analisisnya adalah memastikan apakah institusi menggunakan hyperlink dan email alerts untuk memberikan informasi secara spesifik disesuaikan dengan stakeholders. Jika dicek pada laman http://Kepri.travel/ maka kanal-kanal sambungan dari hyperlink misalnya hingga tingkat tertentu dipandang mampu menggugah emosi pengunjung akan konten yang dimuat. Konten dari hyperlink dari kanal-kanal lain misalnya menampilkan beragam bentuk komunikasi seperti foto, berita, artikel hingga video streaming. Ragam bentuk komunikasi tersebut juga tampil secara berwarna, aktual, estetis serta mudah diakses ketika diunduh.

\section{Memori Terolah}

Memori terolah oleh komputer berarti bahwa informasi dapat diorganisir dan 
diatur secara elektronik, misalnya tersedia alat-alat untuk membantu navigasi laman seperti search engine, sitemaps, dan menu based contents list. Juga tersedia alat-alat analisis yang dapat digunakan stakeholders melalui proses pencarian informasi berdasarkan kebutuhan mereka.

Dalam laman http://Kepri.travel/ terdapat memori terolah dalam bentuk search engine untuk memudahkan pengunjung mencari destinasi fitur yang diharapkan. Fasilitas ini tersebar pada setiap kanal menu yang ada pada laman terkait, juga pada laman-laman hyperlink. Selain itu, situs ini juga menyediakan fasilitas sitemaps dari lokasi-lokasi destinasi wisata di Kepri dalam rangka memudahkan pengunjung melihat posisi lokasi wisata dari peta. Demikian juga dengan menu based content list juga disediakan dalam laman ini sesuai daftar menu yang diharapkan pengunjung lengkap dengan deskripsi lokasi dan panduan kunjungan wisata.

\section{Perekaman Eksternal}

Kriteria perekaman eksternal berhubungan dengan kemampuan media untuk menyediakan rekaman komunikasi, termasuk kemampuan untuk mendokumentasikan (juga memodifikasi) proses komunikasi. Ini misalnya terlihat dari halaman laman menggunakan fasilitas seperti hit counter dan electronic guestbook untuk melacak berapa banyak pihak yang mengakses informasi dalam laman, menyediakan informasi konten laman seperti laporan keberlanjutan dan laporan tahunan untuk beberapa tahun dan adanya fasilitas agar stakeholders dapat mengunduh dan mencetak informasi laman.
Pada laman http://Kepri.travel/ dapat diketahui bahwa laman ini sudah menyediakan fasilitas electronic guestbook berupa kontak pengunjung dengan pengelola laman. Meski demikian belum tersedia fasilitas kanal yang menampilkan komentar dari para pengunjung seperti model portal berita online. Demikian pula belum tersedia konten laman berupa dokumen atau laporan mengenai programprogram pariwisata Kepri secara lengkap antar tahun. Laman ini juga belum menyediakan fasilitas mengunduh atas konten-konten tertentu yang dibutuhkan pengunjung yang mengaksesnya.

\section{Konkurensi}

Konkurensi merujuk pada kemampuan media untuk memfasilitasi interaksi antara banyak pengguna secara simultan. Parameternya adalah dalam halaman laman terdapat fasilitas interaksi melalui email, forum diskusi, bulletin boards, chatroom atau dengan bentuk automatic feedback forms dan electronic surveys.

Pada laman http://Kepri.travel/ dapat dilihat bahwa terdapat fasilitas email pengelola laman untuk menu kegiatan Festival Bahari Kepri 2016, namun belum terdapat fasilitas email pengelola untuk laman http://Kepri.travel/. Demikian pula dengan fasilitas forum diskusi secara online, chatroom maupun online surveys belum tersedia pada laman ini. Sementeara bulletin boards sudah tersedia namun masih terbatas pada agenda kegiatan wisata pada laman terkait.

\section{Kesimpulan}

Berdasarkan uraian di atas maka dapat disimpulkan bahwa secara umum portal 
pariwisata Kepri pada alamat http://Kepri.travel/ secara umum cukup representatif untuk mempromosikan pesona pariwisata di Kepri. Setidaknya hal ini tercermin dari pemenuhan laman terkait pada mayoritas elemen unit analisis laman yakni Kesegeraan, Keragaman Penerima, Kergaman Isyarat, Keragaman Bahasa, Sumber Personal, Memori Terolah, Perekaman Eksternal dan Konkurensi.

Meskipun demikian laman terkait belum menyediakan fasilitas secara optimal pada elemen perekaman eksternal (hit counter dan electronic guestbook dan fasilitas pengunduhan) serta konkurensi (email, forum diskusi, bulletin boards, chatroom atau dengan bentuk automatic feedback forms dan electronic surveys). Untuk itu disarankan pengelola laman melengkapi konten laman dengan fasilitas perekaman eksternal dan konkurensi agar promosi kepariwisataan di Kepri dapat lebih maksimal.

\section{Daftar Pustaka}

Putra, Dedi Kurnia Syah dan Saputri, Nisa Dwi. 2015. "Komunikasi Cyber CSR: Analisis Isi pada Official Laman PT. Bank Pembangunan DaerahJawa Barat dan Banten", Jurnal Channel, Vol. 3, No. 2, Oktober 2015, hal. 17-39.

\section{http://Kepri.travel/}

Hallet, R. W., and Winger, J. K. 2010. Official Tourism Websites: A Discourse Analysis. Perspective. Toronto: Channel View Publications http://Kepri.travel/
Mihajlović, I. 2012. "The Impact of Information and Communication Technology (ICT) as a Key Factor of Tourism Development on the Role of Croatian Travel Agencies" in International Journal of Business and Social Science, 3(24), 151-159

Ritzer, G. and Liska, A. 1997. 'McDisneyization' and 'posttourism': Contemporary perspectives on contemporary tourism. In $\mathrm{C}$. Rojek and J. Urry (eds) Touring Cultures: Transformations of Travel and Theory (pp. 96_109). London: Routledge.

Shanker, D. 2008. "ICT and Tourism: Challenges and Opportunities", paper presented in Conference on Tourism in India - Challenges Ahead, May 15-17. 
Spirit Publik Volume 12, Nomor 1, April 2017 Halaman 1 - 8 